\title{
Prevalence and Genetic Characterization of Cryptosporidium Infection in Java Sparrows (Lonchura oryzivora) in Northern China
}

\author{
Qiu-Xia Yao, ${ }^{1,2}$ Xiao-Xuan Zhang, ${ }^{1,3}$ Kai Chen, ${ }^{1}$ Jian-Gang Ma, ${ }^{1,3}$ Wen-Bin Zheng, \\ Xiao-Qin $\mathrm{Xu}^{2}$ and Xing-Quan $\mathrm{Zhu}{ }^{1,2,3}$ \\ ${ }^{1}$ State Key Laboratory of Veterinary Etiological Biology, Key Laboratory of Veterinary Parasitology of Gansu Province, \\ Lanzhou Veterinary Research Institute, Chinese Academy of Agricultural Sciences, Lanzhou, Gansu Province 730046, China \\ ${ }^{2}$ Jiangsu Co-Innovation Center for Prevention and Control of Important Animal Infectious Diseases and Zoonoses, \\ Yangzhou University College of Veterinary Medicine, Yangzhou, Jiangsu Province 225009, China \\ ${ }^{3}$ College of Animal Science and Technology, Jilin Agricultural University, Changchun, Jilin Province 130118, China
}

Correspondence should be addressed to Xing-Quan Zhu; zhuxingquan@caas.cn

Received 4 February 2017; Accepted 4 June 2017; Published 4 July 2017

Academic Editor: Francesca Mancianti

Copyright (C) 2017 Qiu-Xia Yao et al. This is an open access article distributed under the Creative Commons Attribution License, which permits unrestricted use, distribution, and reproduction in any medium, provided the original work is properly cited.

\begin{abstract}
Cryptosporidiosis is a cosmopolitan parasitosis that affects a wide range of hosts including birds. As information concerning Cryptosporidium in birds is limited, the present study examined the prevalence and genotypes of Cryptosporidium in Java sparrows in Beijing and Shangqiu, northern China. Three hundred and fifty fecal samples were collected from Java sparrows (Lonchura oryzivora, 225 white Java sparrows and 125 gray Java sparrows) in Beijing and Shangqiu in October 2015, and the samples were examined by PCR amplification of the small subunit ribosomal RNA (SSU rRNA) gene. The overall Cryptosporidium prevalence is $13.42 \%$ (47/350), with $16.44 \%$ (37/225) in white Java sparrows and $8.00 \%(10 / 125)$ in gray Java sparrows. Cryptosporidium prevalence was $9.82 \%$ (16/163) in Java sparrows from Beijing and $16.58 \%(31 / 187)$ in Java sparrows from Shangqiu. The prevalence of Cryptosporidium in females and males was $40.63 \%$ (26/64) and $7.34 \%(21 / 286)$, respectively. The Cryptosporidium prevalence in Java sparrows of different ages varied from $10.47 \%$ to $16.33 \%$. Sequence analysis of the SSU rRNA gene revealed that all the samples represented C. baileyi. This is the first report of Cryptosporidium in gray Java sparrows in China, which extend the host range for $C$. baileyi. These results provide baseline information for further studies of molecular epidemiology and control of Cryptosporidium infection in poultry in China.
\end{abstract}

\section{Introduction}

Enteric parasite Cryptosporidium is one of the most important causative agents of gastrointestinal illnesses in humans and animals [1-3]. Food and water contaminated by Cryptosporidium oocysts are the most important resources for human infection [3-5]. Moreover, it can be transmitted to humans by direct contact with infected animals $[3,6]$. Human infection with Cryptosporidium may show symptoms of diarrheal illness and some other severe diseases. Cryptosporidium infection in birds may present symptoms of respiratory disease, digestive symptoms, and renal disease $[7,8]$.
Cryptosporidium infection in birds was firstly recorded in 1929. So far, over 30 avian species have been reported as the hosts of Cryptosporidium in the world [7]. Respiratory symptoms frequently occur in birds, and this infection leads to higher morbidity and mortality in birds, especially in broiler chickens [7]. Recently, more than 17 Cryptosporidium species/genotypes (C. galli, C. baileyi, C. meleagridis, C. hominis, C. parvum, C. muris, Cryptosporidium avian I-V, goose genotypes I-IV, duck genotype, and Eurasian woodcock genotype) have been recorded in birds worldwide [7, 9-13]. Of these, C. hominis, C. parvum, and C. meleagridis are wellknown causative agents of human infection [12]. 
TABLE 1: Factors associated with prevalence of Cryptosporidium in Java sparrows in Beijing and Shangqiu, northern China.

\begin{tabular}{|c|c|c|c|c|c|c|}
\hline Factor & Category & Number positive & Number tested & Prevalence (\%) (95\% CI) & OR $(95 \% \mathrm{CI})$ & $P$ value \\
\hline \multirow{2}{*}{ Region } & Beijing & 16 & 163 & $9.82(5.26-14.38)$ & Reference & \multirow{2}{*}{0.06} \\
\hline & Shangqiu & 31 & 187 & $16.58(11.25-21.91)$ & $0.55(0.29-1.04)$ & \\
\hline \multirow{2}{*}{ Species } & White Java sparrow & 37 & 225 & $16.44(11.60-21.28)$ & Reference & \multirow{2}{*}{0.03} \\
\hline & Gray Java sparrow & 10 & 125 & $8.00(3.24-12.76)$ & $2.26(1.08-4.73)$ & \\
\hline \multirow{2}{*}{ Sex } & Female & 26 & 64 & $40.63(28.60-52.66)$ & Reference & \multirow{2}{*}{$<0.01$} \\
\hline & Male & 21 & 286 & $7.34(2.22-12.46)$ & $8.63(4.43-16.84)$ & \\
\hline \multirow{3}{*}{ Age } & $3 \sim 5$ months & 11 & 92 & $11.95(5.33-18.57)$ & Reference & \multirow{3}{*}{0.38} \\
\hline & $6 \sim 8$ months & 25 & 153 & $16.33(10.47-22.19)$ & $0.70(0.49-2.82)$ & \\
\hline & $>8$ months & 11 & 105 & $10.47(4.61-16.33)$ & & \\
\hline Total & & 47 & 350 & $13.42(9.85-16.99)$ & & \\
\hline
\end{tabular}

In view of such severe situations, a number of studies concerning Cryptosporidium prevalence and genotypes in birds have been conducted worldwide. In China, a few studies on Cryptosporidium infection in birds have been reported in Henan [12], Qinghai [14], and Zhejiang [15] provinces. A preliminary survey indicated that Cryptosporidium could infect white Java sparrows (Lonchura oryzivora) [12], but the number of sampled birds is too small $(n=25)$, which may not reflect the actual prevalence of Cryptosporidium in this bird. Also, no information is available about the prevalence of Cryptosporidium in gray Java sparrows in China. Therefore, we investigated the Cryptosporidium prevalence in Java sparrows (Lonchura oryzivora) in China and assessed its associated risk factors.

\section{Materials and Methods}

2.1. The Investigated Sites. The survey was conducted in Beijing and Shangqiu cities (two main locations of birds' production), northern China. Beijing city $\left(39^{\circ} 26^{\prime}-41^{\circ} 03^{\prime} \mathrm{N}\right.$, $115^{\circ} 25^{\prime}-117^{\circ} 30^{\prime} \mathrm{E}$ ) lies to the south of the Yanshan Mountains with an average altitude of $43.5 \mathrm{~m}$, annual precipitation of $626 \mathrm{~mm}$, and average annual temperature of $12.6^{\circ} \mathrm{C}$. Shangqiu city $\left(114^{\circ} 82^{\prime}-116^{\circ} 45^{\prime} \mathrm{E}, 33^{\circ} 98^{\prime}-34^{\circ} 80^{\prime} \mathrm{N}\right)$ is located in Henan province and has a subhumid warm temperate continental monsoonal climate. The altitude of Shangqiu city ranges from $30 \mathrm{~m}$ to $70 \mathrm{~m}$, and the average annual temperature is $14.2^{\circ} \mathrm{C}$.

2.2. Collection and Preparation of Samples. A total of 350 fecal samples were collected randomly from 225 white Java sparrows (Lonchura oryzivora) and 125 gray Java sparrows (Lonchura oryzivora), of which 163 were obtained from Beijing and 187 were obtained from Shangqiu from pet shops in 2015. Fecal samples were collected by using aseptic cotton and then filtered ( $0.3 \mathrm{~mm}$ wire mesh), and the filtrate was transferred into a $1.5 \mathrm{~mL}$ tube. All the samples were stored at $4^{\circ} \mathrm{C}$ until used for further analysis. Genomic DNA was extracted from feces using a Stool DNA kit (OMEGA, USA) according to the manufacturer's instructions. The DNA samples were stored at $-20^{\circ} \mathrm{C}$ until used. Information about species, origin, gender, and age of Java sparrows was obtained and listed in Table 1.
2.3. PCR Amplification. Cryptosporidium species/genotypes were determined by nested PCR amplification of the small subunit ribosomal RNA (SSU rRNA) gene using primers F1 $\left(5^{\prime}\right.$-CCCATTTCCTTCGAAACAGGA- $\left.3^{\prime}\right)$ and R1 (5'-TTCTAGAGCTAATACATGCG-3') for primary amplification and F2 ( $5^{\prime}$-AAGGAGTAAGGAACAACCTCCA- $\left.3^{\prime}\right)$ and R2 ( $5^{\prime}$-GGAAGGGTTGTATTTATTAGATAAAG-3 ${ }^{\prime}$ ) for secondary amplification $[16,17]$. PCR reaction $(25 \mu \mathrm{L})$ was composed of 1x PCR buffer $\left(\mathrm{Mg}^{2+}\right.$-free $), 2 \mathrm{mM} \mathrm{MgCl} 2,200 \mu \mathrm{M}$ of each deoxyribonucleoside triphosphate (dNTP), $0.4 \mu \mathrm{M}$ of each primer, $0.2 \mathrm{U}$ of HotStart Taq DNA polymerase (Takara, Dalian, China), and $2 \mu \mathrm{L}$ of DNA template. The cycling conditions were $5 \mathrm{~min}$ at $95^{\circ} \mathrm{C}$ for initial denaturation and then 35 cycles of $45 \mathrm{~s}$ at $94^{\circ} \mathrm{C}, 45 \mathrm{~s}$ at $55^{\circ} \mathrm{C}$, and $1 \mathrm{~min}$ at $72^{\circ} \mathrm{C}$, followed by final extension at $72^{\circ} \mathrm{C}$ for $10 \mathrm{~min}$. Both positive and negative controls were included in each test. PCR products were observed under UV light after electrophoresis in $1.5 \%$ agarose gel containing GoldView ${ }^{\mathrm{TM}}$ (Solarbio, Beijing, China).

2.4. Sequencing Analyses. The positive PCR products of Java sparrows were sequenced by GenScript Company (Nanjing, China). Cryptosporidium species were determined by alignment with known reference sequences available in GenBank using BLAST (https://www.ncbi.nlm.nih.gov/BLAST/). Representative nucleotide sequences were deposited in GenBank under accession numbers KY034418-KY034427 and KY962159.

2.5. Statistical Analysis. The variation in Cryptosporidium prevalence $(y)$ of Java sparrows of different geographical location $(x 1)$, age $(x 2)$, species $(x 3)$, and gender $(x 4)$ was analyzed by $\chi^{2}$ test using SPSS 19.0. In the multivariable regression analysis, each of these variables was included in the binary logit model as an independent variable. The best model was judged by Fisher's scoring algorithm. All tests were two-sided, and values of probability $(P)<0.05$ were considered statistically significant. Odds ratios (ORs) and their 95\% confidence intervals (95\% CIs) were estimated to explore the strength of the association between Cryptosporidium positivity and the conditions tested. 


\section{Results and Discussion}

Forty-seven out of 350 Java sparrows (13.42\%) were tested to be Cryptosporidium-positive by nested PCR amplification of the SSU rRNA gene (Table 1). Cryptosporidium prevalence was 9.82\% (16/163) in Beijing and 16.58\% (31/187) in Shangqiu (Table 1). The prevalence in white Java sparrows and gray Java sparrows was $16.44 \%(37 / 225)$ and $8.00 \%(10 / 125)$, respectively (Table 1). Moreover, female Java sparrows $(40.63 \%$, 26/64) had a statistically higher Cryptosporidium prevalence than males $(7.34 \%, 21 / 286)$ (Table 1$)$. The infection rates of Cryptosporidium in the different age ranged from $10.47 \%$ to $16.33 \%$, with the highest prevalence in the 6-8-month group (Table 1), but the difference was not statistically significant among age groups $(P>0.05)$. Species and sex of Java sparrows were considered as main risk factors to influence the positive rate significantly.

Analyses of the obtained SSU rRNA sequences indicated that all of the 47 isolates represented C. baileyi. These sequences were deposited in GenBank under accession numbers KY034418-KY034427 and KY962159. Comparative analyses of all the obtained SSU rRNA sequences with that of the two known reference sequences (C. baileyi, GU816040 and C. baileyi, AF262324) indicated that no variation was found among them.

In this study, the prevalence of Cryptosporidium in Java sparrows is $13.42 \%$, which is higher than the $4.86 \%$ prevalence in birds in Brazil by PCR [11], 8.1\% in white Java sparrows in China by Sheather's sugar flotation technique [12], and $3.22 \%$ in parrots in China by ELISA [2]. Moreover, the Cryptosporidium prevalence of the present study was lower than that in pigeons in Thailand (25\%) [18]. Different age distributions, test methods, geological environment conditions, and the breeding density may contribute to the difference of Cryptosporidium prevalence $[2,19]$.

In the present study, all of the obtained 47 Cryptosporidium isolates belong to C. baileyi. C. baileyi is approximately the most common avian Cryptosporidium [20, 21] because it has been reported in a wide range of avian hosts including chickens, turkeys, ducks, black-billed magpie, common myna, crested lark, Gouldian finch, red-billed leiothrix, mixed-bred falcons, zebra finch, rose-ringed parakeet, white Java sparrow, grey partridge, saffron finch, and ruddy shelducks $[7,12,20-22]$.

\section{Conclusion}

The present study revealed overall Cryptosporidium prevalence of $13.42 \%$ (47/350) with $16.44 \%$ (37/225) in white Java sparrows and $8.00 \%(10 / 125)$ in gray Java sparrows. This is the first report of $C$. baileyi in gray Java sparrows in China, which extend the host for $C$. baileyi. These results provide baseline information for further studies of molecular epidemiology and control of Cryptosporidium infection in poultry in China.

\section{Conflicts of Interest}

The authors declare that there are no conflicts of interest regarding the publication of this paper.

\section{Acknowledgments}

Project support was provided by the Fundamental Research Funds of Chinese Academy of Agricultural Sciences (Grant no. Y2016JC05) and the China Agricultural Science and Technology Innovation Program (ASTIP) (Grant no. CAASASTIP-2014-LVRI-03).

\section{References}

[1] Q. Li, L. Li, W. Tao et al., "Molecular investigation of Cryptosporidium in small caged pets in northeast China: host specificity and zoonotic implications," Parasitology Research, vol. 115, no. 7, pp. 2905-2911, 2016.

[2] X.-X. Zhang, N.-Z. Zhang, G.-H. Zhao, Q. Zhao, and X.-Q. Zhu, "Prevalence and genotyping of Cryptosporidium infection in pet parrots in North China," BioMed Research International, vol. 2015, Article ID 549798, 6 pages, 2015.

[3] G.-H. Zhao, S.-Z. Du, H.-B. Wang et al., "First report of zoonotic Cryptosporidium spp., Giardia intestinalis and Enterocytozoon bieneusi in golden takins (Budorcas taxicolor bedfordi)," Infection, Genetics and Evolution, vol. 34, pp. 394-401, 2015.

[4] Y. Feng and L. Xiao, "Zoonotic potential and molecular epidemiology of Giardia species and giardiasis," Clinical Microbiology Reviews, vol. 24, no. 1, pp. 110-140, 2011.

[5] L. Xiao, "Molecular epidemiology of cryptosporidiosis: an update," Experimental Parasitology, vol. 124, no. 1, pp. 80-89, 2010.

[6] J. Šlapeta, "Cryptosporidiosis and Cryptosporidium species in animals and humans: a thirty colour rainbow?" International Journal for Parasitology, vol. 43, no. 12-13, pp. 957-970, 2013.

[7] U. Ryan, "Cryptosporidium in birds, fish and amphibians," Experimental Parasitology, vol. 124, no. 1, pp. 113-120, 2010.

[8] L. Xiao, R. Fayer, U. Ryan, and S. J. Upton, "Cryptosporidium Taxonomy: recent advances and implications for public health," Clinical Microbiology Reviews, vol. 17, no. 1, pp. 72-97, 2004.

[9] R. S. Gomes, F. Huber, S. Da Silva, and T. C. B. Do Bomfim, "Cryptosporidium spp. parasitize exotic birds that are commercialized in markets, commercial aviaries, and pet shops," Parasitology Research, vol. 110, no. 4, pp. 1363-1370, 2012.

[10] A. A. Nakamura and M. V. Meireles, "Cryptosporidium infections in birds - a review," Revista Brasileira de Parasitologia Veterinaria, vol. 24, no. 3, pp. 253-267, 2015.

[11] A. A. Nakamura, D. C. Simões, R. G. Antunes, D. C. da Silva, and M. V. Meireles, "Molecular characterization of Cryptosporidium spp. from fecal samples of birds kept in captivity in Brazil," Veterinary Parasitology, vol. 166, no. 1-2, pp. 47-51, 2009.

[12] M. Qi, R. Wang, C. Ning et al., "Cryptosporidium spp. in pet birds: genetic diversity and potential public health significance," Experimental Parasitology, vol. 128, no. 4, pp. 336-340, 2011.

[13] U. Ryan, L. Xiao, C. Read, L. Zhou, A. A. Lal, and I. Pavlasek, "Identification of novel Cryptosporidium genotypes from the Czech Republic," Applied and Environmental Microbiology, vol. 69, no. 7, pp. 4302-4307, 2003.

[14] R. Wang, F. Wang, J. Zhao et al., "Cryptosporidium spp. in quails (Coturnix coturnix japonica) in Henan, China: molecular characterization and public health significance," Veterinary Parasitology, vol. 187, no. 3-4, pp. 534-537, 2012.

[15] L. Wang, X. Xue, J. Li, Q. Zhou, Y. Yu, and A. Du, "Cryptosporidiosis in broiler chickens in Zhejiang Province, China: molecular 
characterization of oocysts detected in fecal samples," Parasite, vol. 21, article no. 37, 2014.

[16] S. Y. Qin, X. X. Zhang, and G. H. Zhao, "First report of Cryptosporidium spp. in white yaks in China," Parasites Vectors, vol. 7, 2014.

[17] X.-X. Zhang, W. Cong, J.-G. Ma et al., "First report of Cryptosporidium canis in farmed Arctic foxes (Vulpes lagopus) in China," Parasites and Vectors, vol. 9, no. 1, article 126, 2016.

[18] K. Koompapong, H. Mori, N. Thammasonthijarern et al., "Molecular identification of Cryptosporidium spp. in seagulls, pigeons, dogs, and cats in Thailand," Parasite, vol. 21, article 52, 2014.

[19] J. Huang, D. Yue, M. Qi et al., "Prevalence and molecular characterization of Cryptosporidium spp. and Giardia duodenalis in dairy cattle in Ningxia, northwestern China," BMC Veterinary Research, vol. 10, no. 1, article 292, 2014.

[20] F. Huber, S. da Silva, T. C. B. Bomfim, K. R. S. Teixeira, and A. R. Bello, "Genotypic characterization and phylogenetic analysis of Cryptosporidium sp. from domestic animals in Brazil," Veterinary Parasitology, vol. 150, no. 1-2, pp. 65-74, 2007.

[21] R. Wang, F. Jian, Y. Sun et al., "Large-scale survey of Cryptosporidium spp. in chickens and Pekin ducks (Anas platyrhynchos) in Henan, China: prevalence and molecular characterization," Avian Pathology, vol. 39, no. 6, pp. 447-451, 2010.

[22] Y. R. A. Van Zeeland, N. J. Schoemaker, M. J. L. Kik, and J. W. B. Van Der Giessen, "Upper respiratory tract infection caused by Cryptosporidium baileyi in three mixed-bred falcons (Falco rusticolus x Falco cherrug)," Avian Diseases, vol. 52, no. 2, pp. 357-363, 2008. 

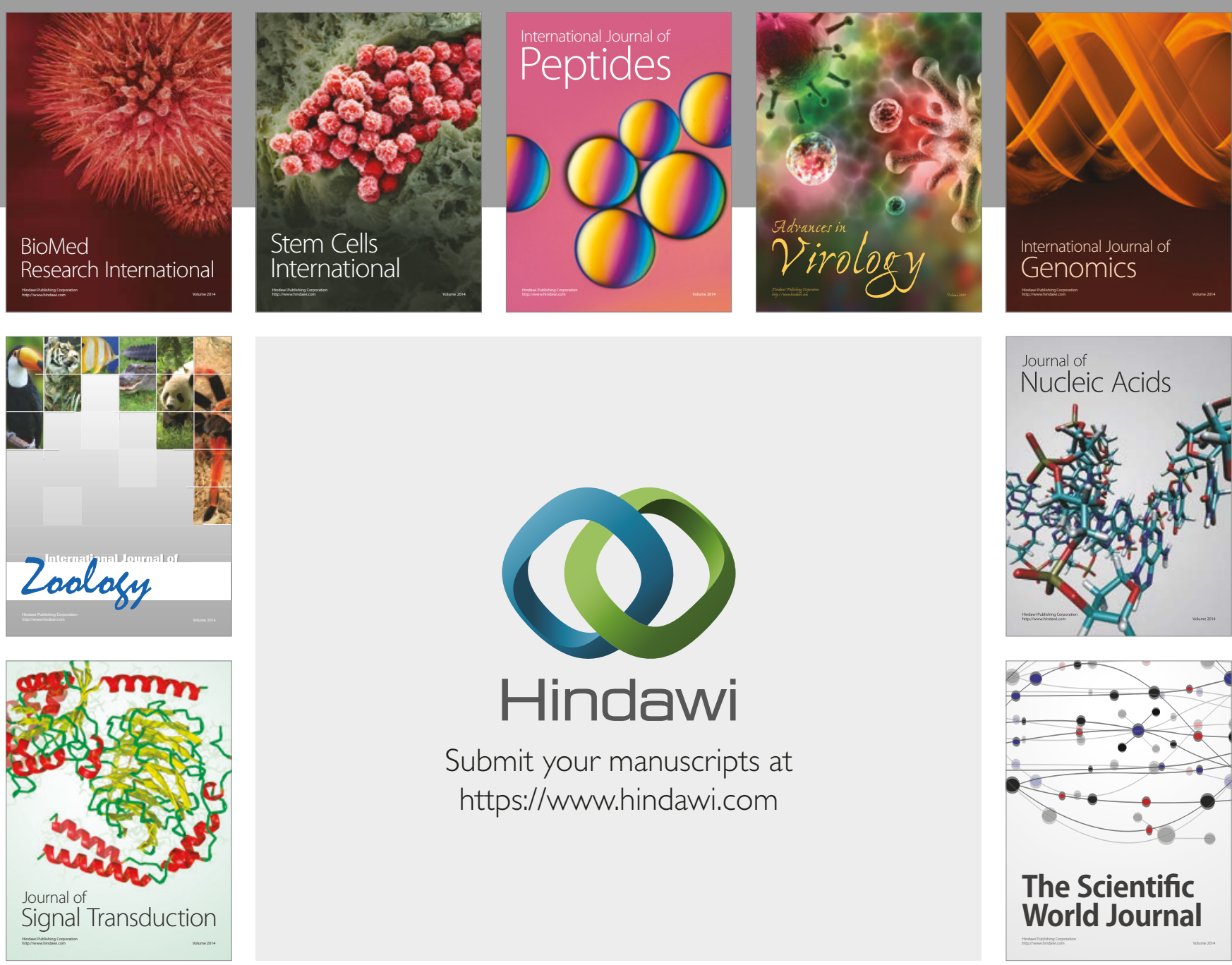

Submit your manuscripts at

https://www.hindawi.com
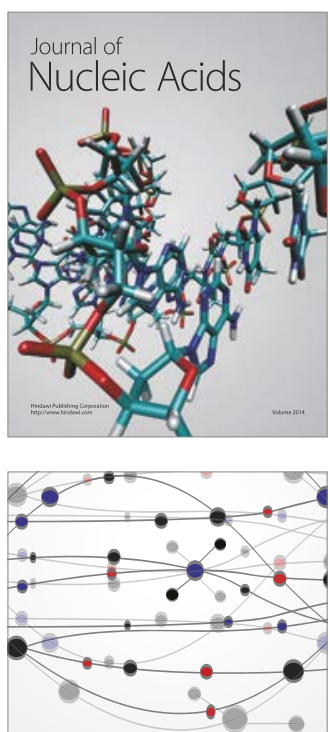

The Scientific World Journal

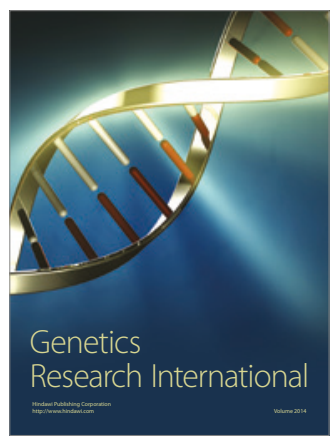

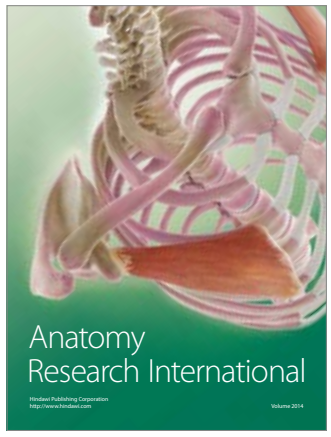

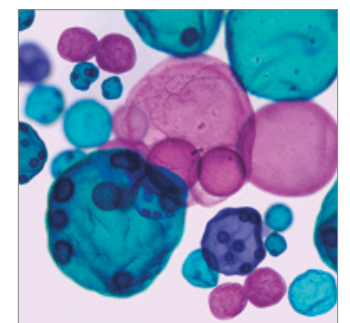

International Journal of Microbiology
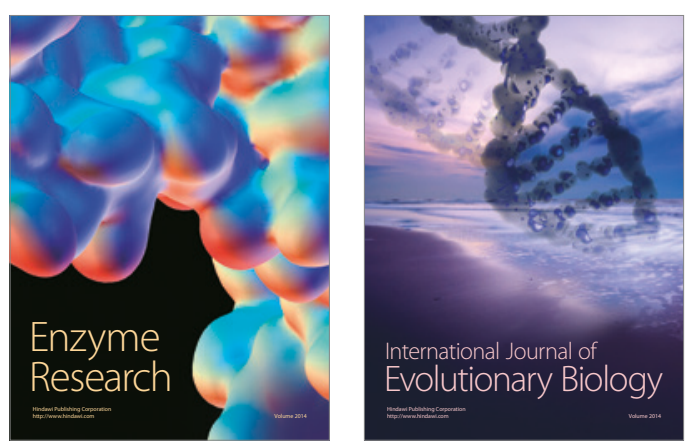
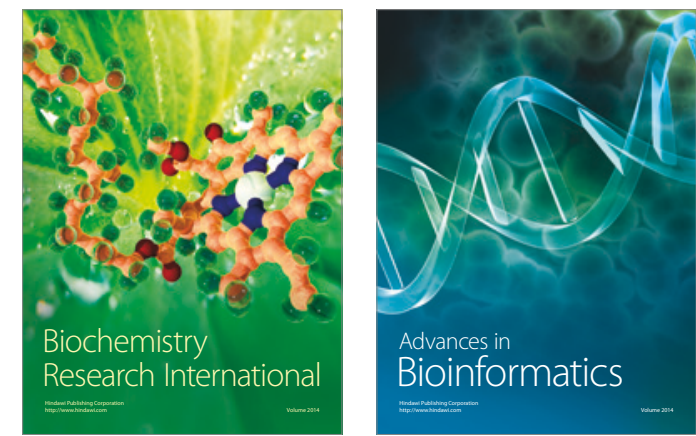

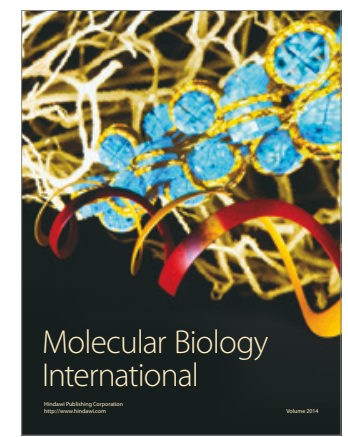

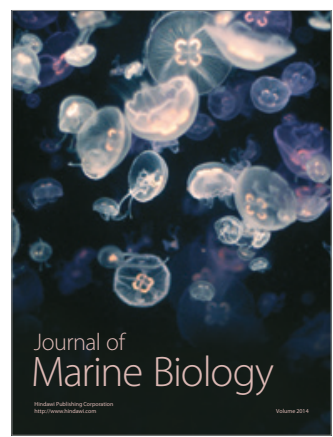

